\title{
Journal of Organizational Change Management
}

What 's in it for me? A managerial perspective on the influence of the psychological contract on attitude towards change

Sjoerd van den Heuvel René Schalk Charissa Freese Volken Timmerman

\section{Article information:}

To cite this document:

Sjoerd van den Heuvel René Schalk Charissa Freese Volken Timmerman , (2016),"What ' s in it for me? A managerial perspective on the influence of the psychological contract on attitude towards change", Journal of Organizational Change Management, Vol. 29 Iss 2 pp. 263 - 292

Permanent link to this document:

http://dx.doi.org/10.1108/JOCM-06-2015-0100

Downloaded on: 30 March 2016, At: 02:09 (PT)

References: this document contains references to 53 other documents.

To copy this document: permissions@emeraldinsight.com

The fulltext of this document has been downloaded 81 times since 2016*

\section{Users who downloaded this article also downloaded:}

(2016),"How does leader communication style promote employees' commitment at times of change?", Journal of Organizational Change Management, Vol. 29 Iss 2 pp. 242-262 http://dx.doi.org/10.1108/ JOCM-11-2014-0204

(2016),"Psychological contract violation and turnover intention: do cultural values matter?", Journal of Managerial Psychology, Vol. 31 Iss 1 pp. 251-264 http://dx.doi.org/10.1108/JMP-10-2013-0337

(2016),"Holistic approach to human resources and organizational acceleration", Journal of Organizational Change Management, Vol. 29 Iss 2 pp. 293-309 http://dx.doi.org/10.1108/ JOCM-11-2014-0210

Access to this document was granted through an Emerald subscription provided by emeraldsrm: 213934 []

\section{For Authors}

If you would like to write for this, or any other Emerald publication, then please use our Emerald for Authors service information about how to choose which publication to write for and submission guidelines are available for all. Please visit www. emeraldinsight.com/ authors for more information.

\section{About Emerald www.emeraldinsight.com}

Emerald is a global publisher linking research and practice to the benefit of society. The company manages a portfolio of more than 290 journals and over 2,350 books and book series volumes, as well as providing an extensive range of online products and additional customer resources and services.

Emerald is both COUNTER 4 and TRANSFER compliant. The organization is a partner of the Committee on Publication Ethics (COPE) and also works with Portico and the LOCKSS initiative for digital archive preservation. 
*Related content and download information correct at time of download. 


\section{What's in it for me? A managerial perspective on the influence of the psychological contract on attitude towards change}

Sjoerd van den Heuvel

University of Twente, Enschede, The Netherlands

René Schalk

Tilburg University, Tilburg, The Netherlands, and

North-West University, Workwell Research Unit, Potchefstroom, South Africa

Charissa Freese

Tilburg University, Tilburg, The Netherlands, and

Volken Timmerman

Volken Timmerman Consultancy, Groningen, The Netherlands

\begin{abstract}
Purpose - The purpose of this paper is to develop a model on how business managers perceive that an employee's psychological contract influences his or her attitude toward an organizational change. More specifically, it aims to provide insight into the managerial views on: first, the affective, behavioral and cognitive responses of employees toward organizational change; second, the pre-change and change antecedents of these responses; and third, the role of the psychological contract as a pre-change antecedent. Design/methodology/approach - Data were collected from in-depth interviews with 39 human resource directors, change managers and management consultants in eight European countries. Based on detailed grounded theory-driven analyses of the qualitative data, a conceptual model was developed.

Findings - Based on the grounded theory analysis, a model emerged that positions the individual change perception and individual answer to the "what's in it for me?" question as central determinants of an employee's attitude toward change. Moreover, the model distinguishes between "influencing" variables that shape the employees' change perception, and "overruling" variables that can potentially reverse the change perceptions.

Practical implications - A strong emphasis on managing the employment relationship by fulfilling mutual obligations and by creating trust will yield more constructive responses to organizational change than focussing on managing an organizational change as an independent event.

Originality/value - As one of the first in its field, this study provides insight in the sense-making processes during organizational change, while adopting a managerial perspective. A grounded theory approach by means of interviewing, serves as a first step toward better understanding of the development of employees' affective, behavioral and cognitive responses to organizational change.

Keywords Trust, Psychological contract, Attitude towards change, What's in it for me

Paper type Research paper
\end{abstract}

\section{Introduction}

For business leaders and change managers, knowledge of the state and content of the psychological contract of employees is highly informative in the context of organizational changes (Rousseau, 2003). The increasing frequency of organizational change means that "promises and deals made in good faith one day may be broken the

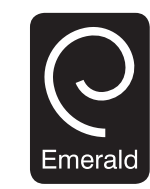

Journal of Organizational Change Management Vol. 29 No. 2, 2016 pp. $263-292$ hing Limited 0953-4814 
JOCM

29,2

next" (Guest, 2004, p. 543). In times of change, organizational agents need to be aware that employment relationships that are characterized by a history of psychological contract breach are likely to "require more extensive overhaul" (Rousseau, 1996, p. 50). The interpretation of an organizational change and the perception of information provided by management are shaped by a change recipient's psychological contract (Rousseau and Tijoriwala, 1999) and general beliefs concerning the employment relationship. Although Rousseau (2003) highlighted the important role that psychological contracts play in a changing workplace, empirical research on the relationship between the psychological contract and an employee's attitude toward change is scarce.

Unlike most change recipients, managers are the ones in the driver's seat of change implementation. They are responsible for defining the desired end state, for determining the outline of the change process and for taking corrective measures during the change implementation. Moreover, they are the ones receiving employee responses to organizational change, and thus are able to judge which factors lead to these responses. Therefore, this study adopts the managerial perspective to gain more insight into the largely unexplored relationship between the psychological contract and attitude toward change.

To position the psychological contract among other antecedents of an employee's attitude toward change, the present study builds on a theoretical framework based on a recently published 60-year review of change recipients' reactions to organizational changes (Oreg et al., 2011). The framework distinguishes categories of pre-change antecedents "which constitute conditions that are independent of the organizational change and which existed prior to the introduction of the change" from categories of change antecedents which "involve aspects of the change itself" (p. 26). In addition, Oreg et al. (2011) categorized the reactions of employees to organizational changes in terms of affect, behavior and cognition. However, this three-dimensional view on employee responses to organizational change introduced by Piderit (2000) has thus far been adopted in only a few empirical studies (see e.g. Oreg, 2006; Van den Heuvel and Schalk, 2009).

The purpose of this study is to build on existing conceptualizations of the psychological contract and attitude toward change to acquire more insight into the managerial perspective on how these concepts are related. The theoretical discussion of both concepts in the following sections aims to synthesize the state of affairs in research on both concepts and to reflect on the relationship between both concepts from a theoretical perspective. In the subsequent sections this relationship is empirically explored from a managerial perspective using a grounded theory approach. In these sections, the following three research questions are addressed:

$R Q 1$. To what extent can a three-dimensional attitude toward change conceptualization be justified according to managers?

$R Q 2$. Which factors influence the attitude of employees to organizational change according to managers?

$R Q 3$. How does the psychological contract influence the attitude of employees to organizational change according to managers?

Based on interview data acquired from 39 human resource directors, change managers and management consultants in eight European countries and 15 multinational organizations, a conceptual model is constructed. 


\section{Attitude toward change}

Researchers as well as practitioners often conceptualize responses to organizational change in terms of resistance (Agócs, 1997; Oreg, 2003; Stanley et al., 2005; McCarthy et al., 2008). However, employees can also respond positively to organizational changes (Lines, 2005; Elias, 2009). The concept readiness to change (e.g. Holt et al., 2007) therefore served as a positive counterpart of resistance to change for a long time. Various other concepts emerged as well, representing either positive responses to change such as openness to change, commitment to change and acceptance of change, as well as more negative ones such as cynicism about change (Wanberg and Banas, 2000; Stanley et al., 2005; Kavanagh and Ashkanasy, 2006; Chen and Wang, 2007). However, each of these conceptualizations is problematic, since it by definition neglects the opposite response and thus does not encompass the broad continuum of potential employee responses. A lack of resistance to change, for example, does not necessarily imply enthusiasm. Similarly, a lack of openness to change does not necessarily mean that employees actively obstruct organizational change. That is why the present study uses the all-embracing and neutral concept of attitude toward change, which does cover the broad continuum of employee responses, ranging from strongly negative to strongly positive (Piderit, 2000; Lines, 2005; Bouckenooghe, 2010).

One of the most influential models in the attitude literature is the tripartite model (Ostrom, 1969; Elizur and Guttman, 1976; Bagozzi, 1978). Piderit (2000) proposed the tripartite view on attitudes in the context of organizational change. Attitude toward change can therefore be defined as a tridimensional state composed of affective, behavioral and cognitive responses to change (Bouckenooghe, 2010). As feelings, behaviors and thoughts about the organizational change can be ambivalent, Piderit (2000) argued that "any definition focusing on one view at the expense of the others seems incomplete" (p. 786). The affective dimension of the attitude construct concerns one's "positive-negative emotional relationship" (Bagozzi, 1978, p. 10), or feelings regarding the change (Oreg, 2006) like anger, happiness or anxiety. In line with Eagly and Chaiken's (1998) work, the affective component can be conceptualized as an employee's feelings, moods and emotions with regard to an organizational change. The behavioral dimension of attitude toward change can be conceptualized as "actions or intention to act in response to the change" (Oreg, 2006, p. 76). Examples are complaining to management, persuading others of the benefits of the change or intentionally reducing one's productivity. Finally, the cognitive dimension of attitude toward change is about thoughts and beliefs, for example about whether or not the change is necessary or beneficial for a particular employee (Piderit, 2000; Oreg, 2006).

\section{Antecedents of attitude toward change}

In times of organizational change, business leaders and change agents are in continuous search of decisive intervention opportunities to steer employee responses to organizational change. This is especially so, given a "growing consensus about the key role that change recipients' reactions to change have in determining the change's potential to succeed" (Oreg et al., 2011, p. 2). Based on their review, Oreg et al. (2011) distinguished two pre-change antecedent categories. First of all, change recipients' characteristics influence attitude toward change. Besides personality traits and demographic variables, this category included an individual's motivational needs and coping styles. The second pre-change antecedent category concerned the internal context of the organization. The degree to which the organizational environment was supportive and management was trustworthy was found to influence employee responses to change. Also the employees' commitment to the organization and the general atmosphere and culture in which the change took place played a role.
Psychological

contract on attitude

265 
JOCM 29,2

266

Next to the two pre-change antecedent categories, Oreg et al. (2011) identified three categories of antecedents that were related to a particular change, the so-called change antecedents. The first antecedent concerned the change process. The antecedents that are most frequently within this category include variables related to the participation in the planning and implementation of the change, the communication and availability of information, and the perceived procedural justice. However, also the principal support - i.e. support for the change from change agents and opinion leaders (Oreg et al., 2011) - and the perceived competence of management to implement the change were found to influence change recipients' reactions to change. The second change antecedent category was related to the perceived benefit or harm caused by the change. Antecedents within this category concerned the anticipated negative or positive outcomes of the change, the perceived job security and the perceived distributive justice, thus whether outcomes of the change are considered fair. The third change antecedent category concerned the change content, i.e. the nature or type of change, as a determinant of employees' attitude toward organizational change. However, only few studies have yet explored this antecedent category.

The psychological contract exists prior to a specific change, and is therefore different from change antecedents such as change information, principal support and procedural justice. The influence of the psychological contract on change recipients' attitude toward change has thus far hardly been subject to scrutiny. Here we consider the psychological contract as a pre-change antecedent, which according to Oreg $e t$ al.'s (2011) model can be classified as an internal context variable. In the next section, the psychological contract will be discussed as well as the theoretical reasoning behind the presumed relationship between the psychological contract and attitude toward change.

\section{The psychological contract}

The psychological contract has become a central framework in understanding the employment relationship and its dynamics. After early writings on the concept by Argyris (1960), Levinson et al. (1962) and Schein (1965), Rousseau made a significant contribution to the further development of the concept. She defined the psychological contract as an individual's beliefs about mutual obligations in the context of the relationship between an employee and an employer (Rousseau, 1990). The obligations that constitute the psychological contract stem from implicit and explicit promises as perceived by the employee. The psychological contract is therefore the subjective belief of these promises. As Dabos and Rousseau (2004) noted, most psychological contract research has focussed on the negative outcomes resulting from psychological contract breach, while "less attention has been paid to the positive or functional outcomes associated with agreement and psychological contract fulfillment" (p. 55). With respect to breach of the psychological contract, the most positive scenario that can occur is that the promises are fully met. However, promises can also be fulfilled more than expected (Turnley and Feldman, 2000). In line with recent psychological contract literature (e.g. Turnley et al., 2003; Lester et al., 2007) this will be taken into account in this study.

Most classifications of work-related outcomes of psychological contract fulfillment point in the direction of affective and behavioral responses. Cognitive responses seem to be underrepresented. However, several outcomes of psychological contract fulfillment, like intention to quit (Robinson and Rousseau, 1994; Tekleab et al., 2005), also consist of beliefs and thoughts. Even affective outcomes such as trust (Robinson, 1996) contain a cognitive component (Zhao et al., 2007). In recent years, several authors have made an attempt to categorize the outcomes of psychological contract breach. 
Zhao et al. (2007) for example conducted a quantitative meta-analysis in which they categorized the work-related outcomes of psychological contract breach into affective reactions, work attitudes and work behavior. In their attempt to improve Kickul et al.'s (2004) categorization of outcomes into attitudes and behaviors, they applied affective event theory to emphasize the role that affective reactions play. They stated that psychological contract breach would result in affective reactions which would consequently contribute to the formation of attitudes and behavior. However, affective event theory's call to position the affective component of the attitude construct as an antecedent of the behavioral and cognitive component (Zhao et al., 2007) contradicts the tripartite model of attitude, which was discussed earlier. According to this widely accepted model, an attitude comprises all three elements, thus affect, behavior and cognition (Bagozzi, 1978). Although the causality among attitude dimensions is subject of an ongoing debate (Piderit, 2000), the present study adopts the view that "variations in evaluation along the particular dimensions of an attitudinal response will cause variations in global attitude" (Piderit, 2000, p. 787). The conclusion is that the psychological contract influences attitude toward change, which comprises affective, behavioral and cognitive elements.

\section{The influence of the psychological contract on attitude toward change}

Reviewing literature on the psychological contract in relation to organizational change reveals that the far majority of studies focus on how organizational changes affect the psychological contract (see e.g. Freese, 2007). More specifically, research has focussed on how these changes affect the psychological contract, resulting in psychological contract breach or violation. Just a few studies considered the psychological contract as a determinant of responses to organizational change, although it has been suggested that this relationship exists (see e.g. Rousseau and Tijoriwala, 1999). According to psychological contract theory, through social exchange and reciprocity mechanisms in the exchange relationship, an employee will seek a certain balance in the exchanges with the organization. A perceived imbalance of the exchange can, for example, lead to psychological contract breach, less trust in the organization and organizational cynicism (Robinson, 1996; Johnson and O'Leary-Kelly, 2003). Such distortions of the relationship between an employee and the employer will have a negative impact on the perceptions of organizational change. Pate et al. (2000), for instance, claim that "when organizations are trying to secure important organizational changes, low trust relations and high degrees of cynicism may combine to significantly limit the degree of change that can be achieved" (p. 486). According to Pate et al., this is because "increasing levels of cynicism could become a self-fulfilling prophecy that makes subsequent changes increasingly more difficult to achieve" (p. 484). Rousseau (1998) argued with respect to the psychological contract and responses to organizational change that transactional psychological contracts would be associated with higher resistance to change, whereas relational psychological contracts would be related to change acceptance. Empirical evidence for a relationship between the psychological contract and resistance to change was found in a study of Van den Heuvel and Schalk (2009) among 208 employees of ten Dutch organizations. The results showed that fulfillment of the organization side of the psychological contract was negatively related to affective resistance to change. Folger and Skarlicki (1999), who elaborated on how distributive, procedural and interactional justice interact to predict resistance to change, argued that "resisting organizational change is one response to a psychological contract violation" (p. 40). In sum, although there are indications that the psychological
Psychological contract on attitude 
JOCM

29,2

268

contract influences employee attitudes toward change, substantial empirical evidence is lacking with respect to both the employee's and employer's (managerial) perspective.

Our research questions refer to the managerial perspective on the relationship between the psychological contract and attitude toward change. We opted to use a grounded theory approach by means of interviewing as a first step toward a better understanding of the presumed relationships. This inductive approach aims to build theories, theoretical models or concepts by starting from data, instead of from already existing theories (Baker, 1999). The aim of this study is to construct a conceptual model.

\section{Method}

Sample

In line with the main aim of the current study to gain a broad insight into the managerial perspective on the relationship between the psychological contract and attitude toward change, we selected a diverse set of respondents. We sought to achieve diversity with respect to position (HR director, change manager, management consultant), type of industry, and country in Western Europe. Based on these criteria, potential respondents were identified and approached through the social networks of the authors. In total, 39 experienced human resource directors, change managers and management consultants were interviewed for this study. The sample included 20 men and 19 women. Since a point of saturation in the concepts and relationships coming forward from the interviews was reached after about 30 interviews, it was decided not to schedule additional interviews after the 39 planned interviews. The 39 respondents were located in Belgium (4), France (4), Germany (7), Italy (7), The Netherlands (2), Portugal (2), Spain (7) and Switzerland (6). All respondents were employed by multinational organizations from various industrial sectors. Participating organizations were active in banking, retail, IT, pharmacy, welding, power generation, petro chemistry, aluminum production, rail transport, cement production, telecommunication and business consultancy. A total of 15 multinational organizations, ranging in size from 900 to 90,000 employees, participated in the study.

\section{Data collection}

Data were collected through 39 semi-structured interviews with a duration of approximately one hour, which were conducted by a single interviewer from the end of April-June 2009. Six interviews were conducted in Dutch, while in the remaining 33 interviews the language was English. All interviews (except for one interview by telephone) were held face to face at the interviewees' office location.

A uniform interview protocol was followed for all respondents. At the beginning of each interview the respondents were assured that the interview was strictly confidential, and that quotations used in publications on the research could not be traced back to them or their organization. All the respondents gave their permission to audio-record the interview.

In line with the three research questions addressed in this study, three themes were explored during the interviews. The first theme focussed on the reactions, responses or attitudes that the managers had witnessed among employees in times of organizational change. The questions asked on this theme served to obtain more insight into the extent to which all three dimensions of the attitude toward change construct are present in times of organizational change, and thus whether the three-dimensional attitude toward change construct can be justified from a managerial perspective. 
The second theme focussed on the factors that caused these various reactions, responses or attitudes toward the change, according to the managers. For this theme, the focus was not only on factors that can be influenced by management practices and can therefore be viewed as opportunities for intervention to influence employees' responses to organizational change. Factors that are difficult or even impossible to influence by management or change agents, such as contextual factors, were considered as well.

The third theme explored the influence of psychological contract on an employee's

Psychological contract on attitude

269 attitude toward organizational change, according to the managers. The respondents were asked to elaborate from their professional perspective on how, if at all, the two concepts are related. In line with the definition presented earlier, the psychological contract was conceptualized as the individual perception of mutual implicit and explicit promises between an organization and an employee.

For each of the three themes, several predetermined questions were formulated. Depending on the characteristics of the organization, on the respondent and on the answers given to the predetermined questions, additional sub-questions were asked. Furthermore, the respondents were asked to answer the interview questions based on their experiences as a professional throughout their entire career, so not only based on their experiences in their current organization or job role.

\section{Data analysis}

All audio recordings of the interviews were literally transcribed and the transcriptions were thoroughly checked by the interviewer. After the transcription of the interviews, a member check was carried out by sending each respondent the transcript of the interview on which he or she could comment. As Lincoln and Guba (1985) point out in their prominent work on naturalistic inquiries, several methods can be used to assure the validity and trustworthiness of qualitative research. They state that member checking is the "most crucial technique for establishing credibility" (p. 314), because it enables respondents to correct errors of fact and to provide additional information when desired. Additionally this takes away the respondent's opportunity to disagree with the original data at a later stage of the research. Besides some minor textual remarks, no content-related feedback was received from the respondents.

In line with the work of Strauss and Corbin (1998), a grounded approach was used to analyze the transcripts of the interviews, which amounted to a highly structured process to condense the large amount of raw data into categories, to develop preliminary concepts, and to eventually determine the central themes, concepts and interrelations. Spencer et al. (2003a) refer to these phases as data management, descriptive accounts and explanatory accounts, while others like Dougherty (2004) talk about open coding, axial coding and selective coding. The present study adopts the latter concepts. In the next part, each of these three phases in the coding process will be explained.

Open coding. As Strauss and Corbin (1990) noted, open coding involves "breaking down, examining, comparing, conceptualizing, and categorizing data" (p. 61). The primary aim of the open coding phase therefore was to make a first attempt to condense the raw data into preliminary categories, by coding respondents' quotes and by subsequently sorting and grouping the emerged codes. To avoid being directed by already existing theoretical categorizations as much as possible, no a priori codes were created. A codebook was created in Microsoft Excel containing three initial chapters corresponding with the three research questions addressed in this study, namely, "Chapter Y-Attitude toward change," "Chapter X-Influencers of attitude toward 
JOCM 29,2

change," and "Chapter PC-Psychological contract." For "Chapter Y-Attitude toward change," three preliminary subchapters were created, namely, "Y-A," "Y-B" and "Y-C," which represented, respectively the affective, behavioral and cognitive attitude toward change dimension. Every code that was created through the coding process started with the abbreviation of the category to which it was assigned, for example "Y-Worrying," "X-Sincere communication" or "PC-Realistic promises." While familiarizing oneself with the data during the process of transcribing the audio recordings, the first author identified 14 subthemes, which formed (together with the three preliminary attitude toward change subchapters) the initial subchapters in the codebook.

The actual coding of the raw data were performed by carefully reading the full transcripts of all 39 interviews, and simultaneously adding a representative code to illustrative, explanatory or striking words, phrases and paragraphs about events, examples, relationships and to concluding remarks that had some bearing on one of the three research questions. ATLAS.ti software was used to support the coding of the data. Each time a new code was created, the name of this code was added to the codebook. If the code fitted one of the initial subthemes of the codebook, the code was assigned to this subtheme. If not, an additional subtheme was created. The open coding process required a continuous deliberation on whether a respondent's quote required a new code, whether the quote fitted an already existing code, whether an already existing code should be renamed, or whether subthemes should be renamed. This process led to the emergence of codes such as "X-1.19 Sincere communication" that were part of the subtheme "X-1 Communication." If respondents mentioned a relationship between two or more concepts, this was captured in the code as well. In such codes, the concepts as well as the direction of the relationship were captured. An example of such a relational code is "PC-OS1.1 FF more $\rightarrow$ more positive toward change" which represents a quote indicating that a higher fulfillment $(\mathrm{FF})$ of the organization side (OS) of the psychological contract (PC) leads to a more positive response toward a change. Obviously, these relational codes were very helpful during the selective coding phase, when constructing the conceptual model.

Axial coding. As described by Strauss and Corbin (1998), in axial coding "categories are related to their subcategories to form more precise and complete explanations about phenomena" (p. 124). In this phase the analyst method framework as described by Spencer et al. (2003b) was used to order, condense and synthesize the raw data underlying the codes created during the open coding phase. This matrix-based analytical method allows for a systematic analysis of qualitative data, since it results in condensed raw data which is arranged per respondent and per theme or subtheme (Spencer et al., 2003b). At the start of the axial coding phase, a matrix was created in a Microsoft Excel worksheet. All 39 respondents were allocated a separate row in the worksheet. In the first column the respondent's name, gender, country, company and position were stated to facilitate navigation and interpretation during the analytical process. Based on the key interview questions and the grouping of the codes that emerged from the open coding phase, eight subthemes were defined and assigned to the columns. For the first "Y-Attitude toward change" theme, the columns "Y-1 Reactions, responses or attitude of employees toward and during organizational change" and "Y-2 Nature of the reactions, responses or attitudes toward organizational change" were created. For the second "X-Influencers of attitude toward change" theme, the columns "X-1 Antecedents of reactions, responses or attitudes toward organizational change" and "X-2 Context factors influencing the reactions, responses 
or attitudes toward organizational change" were created. For the third "PCPsychological contract" theme, the columns "PC-1 Influence fulfillment organizationside psychological contract on attitude toward change," "PC-2 Influence fulfillment employee-side psychological contract on attitude toward change," "PC-3 Additional psychological contract fulfillment/breach/violation," and "PC-4 Influence content psychological contract on attitude toward change" were created. This structure enabled the researchers throughout the entire analytical process: first, to search through (sub) themes across different respondents; second, to search for associations between phenomena within a single respondent; and third, to search for associations in phenomena between groups of respondents.

In order to condense the coded parts of the transcripts, each quotation was summarized into a single sentence. Because "it is essential that the analytic ideas and concepts that are developed are rooted within the data, rather than simply superimposed" (Spencer et al., 2003a, p. 210), characteristic words used by the respondents were captured in the condensed sentences without rephrasing them. Subsequently, the summarizing sentences were placed in the matrix cell that corresponded with the particular respondent and subtheme. As emphasized by Spencer et al. (2003a), it is important to be able to easily access the original data in all stages of the analytical process. Therefore, each quotation for which a summarizing sentence was created was assigned an additional numerical code, starting with 0001 , followed by 0002 and so on. This numerical code was placed after its corresponding summarizing sentence in the matrix. This procedure led to the creation of 1,030 additional codes. These numerical codes and their corresponding quotations were listed in a separate text file. Besides the digital version of this quotation list and matrix, a printed quotation book and matrix book were created to facilitate the remaining analytical process.

The next step in the axial coding process was to identify substantive concepts from the condensed data in the matrix. This was a highly iterative process that started with carefully reading down columns of the matrix, in order to construe a preliminary list of central concepts per theme. Consequently, all content from the matrix, i.e. the summarizing sentences and their corresponding numerical codes, were copied into a separate text file while retaining the organization per subtheme. Then, a first attempt was made to cluster the sentences by coloring-related sentences and assigning them to one of the preliminary concepts. For example, the sentence and numerical code "Trust in leadership results in more willingness to embrace the change and believe that something good will come out of the change (0204)" was clustered under the preliminary central concept "Trust." During this iterative process preliminary concepts were rephrased, new concepts emerged and sentences were reassigned. This process continued until all sentences were assigned to one of the final set of 42 central concepts.

The final step in the axial coding process concerned the categorization of the concepts. It should be noted that the present study does not consider categories as standardized variables, but as groups of concepts that need to be broken down into standardized variables and require operationalization before they can be applied in quantitative research. The categories that comprised the substantive concepts thus required a higher level of abstraction. As a result, category names showed less similarity with the original terminology used by the respondents than, for example code names or the summarizing sentences in the matrix. Based on their similarities, dependency or coherence, the 42 central concepts were categorized into 21 final categories. For example, the concepts "Participation in change" and "Degree of 
JOCM 29,2

272 imposing" were categorized into "Involvement." The model to be presented later consists of these 21 categories.

Selective coding. The selective coding process served to identify the core category or categories, to relate them systematically to the other categories and to validate the relationships by testing hypothetical relationships between the categories (Strauss and Corbin, 1998).

The first step in the selective coding process was to identify the central relationships between the categories per respondent. This was done by reading through the synthesized data in the matrix per row (i.e. respondent) and across columns (i.e. subthemes). The numerical codes assigned to the quotations enabled the researchers to swiftly refer back to the original quotations in the codebook and to easily identify the category to which the summarizing sentence was assigned. All relationships were plotted in a single graphic file, which resulted in the emergence of a preliminary conceptual model.

The second step was to determine the core categories. According to Strauss and Corbin (1998), key criteria to classify categories as core categories are that: first, they are central in a way that all other major categories can be related to them; second, they appear frequently in the data, preferably in most of the single cases; and third, the reasoning behind the relations with other major categories is logical and consistent. Based on these criteria, four core categories were identified, namely, "Understanding of change," "Perceived need for change," "Degree personally affected" and "Expected individual consequences." These four categories were clustered into two categories with a higher level of abstraction. "Understanding of change" and "Perceived need for change" were clustered into "Change perception," while "Degree personally affected" and "Expected individual consequences" were clustered into "What's in it for me." These two clusters form the core categories of the conceptual model.

The third step in the selective coding process was to systematically build the storyline of the conceptual model by relating all remaining categories to the selected core categories and by systematically validating these suggested relationships. The main inputs for this exercise were the graphic file depicting the preliminary conceptual model, the text file created during the axial coding phase in which all the summarizing sentences were assigned to the 21 final categories, and the quotation book. The process of relating all categories to the central variables was again a highly iterative process of reading through the summarizing sentences and referring back to the original quotations, which assured constant validation of the presumed relationships. During this process, three category groups emerged in addition to the group of core categories. The first group of categories concerned the affective, behavioral and cognitive responses of employees to organizational changes, and was labeled by the researchers as outcome categories. Second, there were categories that influence the employee's sense-making process and thus how the employees perceive the change, how well they understand the change and whether or not they evaluate the change as beneficial or harmful for themselves. These categories thus directly influence the core categories, and were therefore labeled influencing categories. Third, there were categories that according to the respondents were much stronger determinants of employees' eventual responses to organizational change than the influencing categories. For these other categories, the potential benefit or harm caused by the change did not seem to be of much significance. Respondents, for example indicated that in case of a lack of trust in management, no positive contribution to the change could be expected, and that if trust had been broken in a prior change, it 
would be hard to mobilize employees a second or third time. Another example concerns the availability of alternatives for employees. Respondents indicated that if it is hard for employees to find a new job elsewhere, either because of one's skill or market circumstances, they will not put their jobs at risk by obstructing the change. This third group of categories was therefore labeled as overruling categories, since they have the potential to overrule the answer to the "what's in it for me" question and thus to cause a negative attitude toward change, whereas from a theoretical standpoint a positive response would be expected (and vice versa).

In the next section the results of the analyses will be presented for all 21 categories, to serve as basis for the conceptual model to be constructed at the end of the results section.

\section{Results}

This section presents the main results for each of the 21 categories that emerged from the axial coding phase. These categories are organized per category group, starting with the outcome categories, followed by the core categories, the influencing categories, and finally the overruling categories. An overview of all categories derived from the analyses is offered in Table I. At the end of this results section, the conceptual model that emerged from the selective coding phase is presented.

\section{Outcome categories}

Affective responses toward change. According to the respondents, organizational changes provoke a variety of affective responses among employees. These responses include include negative responses such as panic, anger, uncertainty, anxiety, worries and feelings of frustration and disappointment, as well as positive responses like

\begin{tabular}{lll}
\hline Category group & Categories & Category characteristics/cluster \\
\hline \multirow{2}{*}{ Outcome categories } & Affective responses toward change & Attitude toward change cluster \\
& Behavioral responses toward change & Attitude toward change cluster \\
Core categories & Cognitive responses toward change & Attitude toward change cluster \\
& Understanding of change & Change perception cluster \\
& Perceived need for change & Change perception cluster \\
Degree personally affected & "What's in it for me" cluster \\
categories & Expected individual consequences & "What's in it for me" cluster \\
& Communication & Change antecedent \\
& Leadership & Change antecedent \\
& Involvement & Change antecedent \\
& Tersonality & Pre-change antecedent, individual level \\
& Change culture & Pre-change antecedent, individual level \\
& Corporate culture & Pre-change antecedent, organizational \\
& & level \\
& Labor unions & Pre-change antecedent, organizational \\
& National differences & level \\
Psychological contract content & Pre-change antecedent, societal level \\
Ability to change & Pre-change antecedent, societal level \\
& Availability of alternatives & Pre-change antecedent, individual level \\
& Prust & Change antecedent \\
& Psychological contract state & Pre-change antecedent, societal level \\
& & Pre-change antecedent, individual level \\
& Pre-change antecedent, individual level
\end{tabular}

Psychological contract on attitude
Table I.

Overview of categories derived from the analyses 
JOCM 29,2

\section{4}

enthusiasm, happiness and eagerness. A Swiss Organizational Development manager of a leading global production organization illustrated the variety of affective responses that can emerge in times of organizational change:

I guess I've met with a huge variety of human feelings depending on the change context. I've met people that were frustrated. I've met people that were angry, furious even. Some were in despair. Some were eager, enthusiastic, looking forward to, being happy about the change. I've seen people cry. I guess - yes - throughout my career [...] I think, give me a feeling, and I probably could give you a situation where I've encountered that feeling.

However, the affective responses of uncertainty and anxiety, primarily mentioned as an unavoidable consequence of a lack of information and communication, were mentioned most frequently and were indicated as the most common initial response to an impending change.

Behavioral responses toward change. The respondents reported that the behavioral responses most frequently encountered were verbal expressions of disagreement toward colleagues or management. Examples given included gossiping, complaining, openly expressing criticism, raising concerns, asking critical questions and talking negatively about the change. However, other behavioral responses, both positive and negative, were reported as well. Positive behaviors that were mentioned were eagerness, pro-active exploration of the change, positive talking about the change, helpfulness, flexibility, cooperation with the change, attempts to persuade others, efforts to promote oneself as an advocate of the change process, continuing to perform regular activities as a means of supporting the own business or client, and demonstrating pro-activeness. It was noted that these behaviors could either be a natural consequence of intrinsic motivation, as well as a strategic attempt to capture the attention of by management. The negative behaviors mentioned by respondents can be divided into passive and active behaviors. Examples of passive behaviors were a wait-and-see attitude and behavior aimed at making oneself as invisible as possible, while waiting for the change to be over. Examples of more active negative behaviors included reducing the effort and energy put into one's work, which could lead to either consciously or unconsciously providing wrong information, starting later and leaving earlier from the office, working at home instead of at the office, sticking to prior ways of working or reverting to prior ways of working. A national HR director of a global retail organization gave a striking illustration of what sticking to prior ways of working could look like in practice, regardless whether this example illustrates active negative behavior or great dedication:

There's someone here, over there in the corner, she has been with [organization] for 25 years, so she was employee 002 . She has experienced everything, and always from a payroll position. She has her own systems which she has built over these 25 years. She went along with some system upgrades, but actually, she still does what she did 25 years ago. She keeps everything on paper. So her binders [...] They are gigantic! It is quite magnificent too. Well [...] it's almost a museum. But if I need something, then she always finds it. She prints every e-mail and keeps it. While you could do that just as well with disks or USB-sticks [...] And then you can say whatever you want, and she will do that, but she won't give up this parallel system.

The interviewees noted that depending on labor market circumstances, internal opportunities, or one's personal situation, some employees choose to perform as a minimal player. Others may ask for an exit package or just leave the organization. Additional active negative behaviors that the respondents had witnessed were 
employees who were up in arms, were rebellious, reluctant to share information or actively trying to block the change, for example by involving labor parties and unions.

Cognitive responses toward change. According to the managers, employees' cognitive responses to an organizational change were primarily focussed on thoughts regarding the consequences of the change. Although thinking about the consequences for the colleagues or the organization was mentioned several times, the vast majority of the respondents noted that employees primarily considered their individual consequences. More specifically, the consequences for one's own job, way of working, working life, comfort zone, relation to colleagues and relation to management were mentioned as cognitive responses to change. The key notion mentioned in this respect was "what's in it for me." It was stated repeatedly that if an employee sincerely believes he or she can personally benefit from the change, whether it concerns reward, job content or another element relevant to the particular individual, this employee will demonstrate considerably less opposition to the change. The respondent's perception that personal benefits were more decisive for an employee's attitude toward change than the perceived organizational benefits was nicely illustrated by an Italian change consultant, who noted at the end of the interview:

We didn't cover the personal benefit you can see in the changes. Because I think that every employee can look at the benefits for the company and the benefits for the entire organization, for the business, etcetera, etcetera. But at the end it's a personal contract. So anyone can think what is in it for me in these changes. And that's why you can have the difference between the different employees.

Concerning the perceived consequences of the change, several respondents noted the different general dispositional perspectives employees can have about these consequences. It was mentioned that certain people do not think in terms of consequences, but in terms of opportunities. One respondent indicated that talented people in particular would think about consequences in terms of future opportunities rather than threats. Other cognitive responses to change mentioned by the respondents included trying to understand the rationale for the change, trying to understand what will happen during the change period, thinking about whether or not the change can be trusted, thinking about what change could occur in the future, and thinking about how they can personally influence the change. Finally, confusion and fantasizing about doom scenarios were mentioned as cognitive responses resulting from a lack of knowledge or information about the change.

The preceding results demonstrate that a primary focus on behavior and visible responses to the change neglects the important role of feelings and thoughts in the overall attitude of an employee toward a change. Not only do the results show a considerable variety of affective and cognitive responses, but various respondents also stressed that feelings and thoughts are often at odds with the visible behavior of the individuals. A Dutch People Strategy manager, for example stated:

Well, you know, I very much believe in the iceberg metaphor. You have all kinds of pyramidlike things, by which you cannot always get insight in the beliefs. So I don't see them, unless people express them directly in their behavior or in their talking.

This same manager also indicated that employees' eventual behavior toward change depended on their feelings and thoughts. However, she noted that it also depends on the profile and personality of the individual whether emotional or rational considerations prevail and thus influence the eventual behavioral responses to the change. 
JOCM

29,2

\section{Core categories}

Understanding of change. An employee's understanding of the change was mentioned by the respondents primarily in relation to the roadmap of the change, i.e. the change process ahead. According to the respondents, employees need to understand where the change is heading to, in what direction the organization will move, what the different phases of the change will look like and to what end state the change will lead. Moreover, the bigger picture should be made clear by management, so that an employee understands the vision behind the change, the ultimate goal and the fit of the change with the strategy of the organization. In other words, employees need to understand the rationale behind the change. The European HR director of a global cement production organization emphasized the important role communication plays in creating this understanding:

If the employee understands the change, there is no problem. [...] I think what happens is if the employee doesn't understand the rationale of the change, then they go back on "yes, this is what was promised, this is why I was appointed, this was my job, these was my conditions", then they fall back on what they believe are their securities. [...] But there must be a lot of communication and there must be a lot of time for questions. The employees can ask questions "Why?", "What's happening?”, "For what reason?”, "Where are we going?".

Perceived need for change. Another factor mentioned by the respondents during most interviews concerns the necessity of the change, as perceived by the employee. Thus, why does the organization need this change and why do I as an individual employee need this change? The respondents stressed the importance for organizations and management to formulate a clear and unambiguous answer to the "why question" in the mind of employees. A perceived need for change, which was often referred to as "burning platform" during the interviews, results in more acceptance of the change. The "golden city" metaphor was also used several times to illustrate that it can be hard for employees to understand why they should change or to perceive any sense of urgency when working in a "golden city," i.e. a well-performing organization. An Italian Vice-President of a global consultancy firm noted:

I'm currently working in a company, a very successful company here in Italy, a very rich, a very well-known one in the market. With a strong brand. Changing something in that company is very complicated. Because, why change something that is doing very, very well? $[\ldots]$ The acceptance of change is very difficult, because OK, we make a lot of money, we are the first in the market, nobody has a product like us. Why do we have to change? [...] So it's more difficult to change in that company, in which everything is going well, than in another company in which "if you don't do that, you die". Let's take Fiat for example. The Fiat case. In two years, the new CEO made an extraordinary work. They came from a situation in which Fiat was close to closure. Currently, Fiat is leading the change of the automotive industry. Why? Because it was very tight and focused; if we don't do that, we are dying.

Degree personally affected. Most respondents also pointed to the degree to which employees are personally affected by the organizational change. It was mentioned that if an individual employee is not much affected by a change, his or her response to that change is likely to be less extreme and often more supportive, compared to a situation in which an employee's job or private situation is directly impacted by the change. In the latter case, the status quo is affected at an individual level, which results in more extreme responses, according to the respondents. However, an employee's perception of the extent to which he or she will be affected is not likely to be a stable state of mind 
throughout the change process. It was stated that at the beginning of the change process, the management often sketches just the outlines of a change, which is perhaps still months away. The individual's perception of the personal impact of a change is likely to become clearer as the change is progressing and the targeted end state draws nearer. The more an employee perceives that he or she is affected by the change, the more extreme the response will be. However, it was indicated that the actual nature of the response, thus whether the response is positive or negative, depends on the expected consequences for the individual.

Expected individual consequences. The expected individual consequences of a change, at least as perceived by the employee, turned out to be the most crucial final determinant of one's attitude to a change. Even though the necessity of a change for the organization as a whole or for the sake of efficiency or effectiveness, the individual benefits for the individual employee should be abundantly clear in order for him or her to assume a genuinely positive attitude. Potential benefits mentioned by the respondents included an enhanced powerbase, increased opportunities for professional development, more autonomy or an improved compensation package. Benefits may also relate to a better fit with private circumstances or an improved work-life balance. What will actually benefit an employee therefore differs per individual. A German COO emphasized how important it is for management to adequately and pro-actively address the individual's "what's in it for me" question:

For me organizational change and the resistance to organizational change are connected to the personal "what's in it for me" character. The more you can forecast the interest of the employee and you can fulfill this, the more happiness you will create and the less resistance you will get.

\section{Influencing categories}

Communication. The importance of communication featured prominently in the responses of almost all respondents. The general perception was that proper communication can diminish negative responses to a change such as anxiety, uncertainty, gossiping, opposition and quitting. The communication-related responses of the interviewees can roughly be categorized as addressing either what is communicated, or to who is being communicated?

First of all, regarding what is communicated, respondents emphasized the importance of communicating the "why" of the change, i.e. the rationale for the change, the vision behind it, the burning platform and the necessity of change. Explaining these factors will increase the perceived legitimacy of the change among employees. Furthermore, the roadmap following from the change objectives should be explained, which not only means explaining the successive steps but especially also the projected end state. Less specific though mentioned frequently and explicitly were the terms "transparency" and "honesty." They seem to serve as principles that guide concrete communication activities. As stated by the respondents, transparency means that you also communicate change aspects that are negative for the change recipients, such as redundancies. Moreover, management should also be transparent about aspects that cannot be divulged to employees, for example head office decisions. Furthermore, honesty and transparency imply that, whenever this is the case, the change agents admit that they cannot (yet) foresee particular aspects of the change, for example aspects relating to the timeframe of the change program or to the consequences of the change for individuals.
Psychological contract on attitude

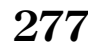


JOCM 29,2

Regarding the second communication element, to whom is being communicated, much emphasis was put on the importance of individualized and segmented communication. Communication must explicate what the impact and the consequences of the change will be for each individual employee. Although one respondent mentioned that group communication could prevent the perception that a particular measure, like a salary freeze, will only apply to certain individuals or to a limited group of people, most respondents argued that communication should be individualized and personalized. Further, "segmented communication" means that change agents should provide the appropriate information to each target group. Therefore, a one-size-fits-all approach does not apply to communication in change processes. Respondents noted that for that reason, the selection of stakeholders that provide communication and the media that are used for communication should be carefully considered.

Finally, some respondents emphasized the importance of continuous communication throughout the entire change process starting from day one, and the availability of feedback channels to stimulate a dialogue rather than having one-way communication only. The prominent positioning of these communication elements in the interviews underlines their importance in practice.

Leadership. During the interviews, leadership was indicated as having the potential to make employees start moving in a certain direction. It was mentioned that a change needs leaders rather than managers to create commitment, acceptance, trust in the change and thus to really "make things happen." According to the respondents, leaders serve as role models in times of change and a lack of leadership can therefore generate negativity. The central role that leaders play in communicating the change was also emphasized. A few respondents noted that the direct supervisor's support for the change may determine the attitude of an individual employee to a greater extent than top management's support. Still, top management support was mentioned as a prerequisite for a successful change implementation. At the same time, as some respondents illustrated, organizational changes can create confusion about who the leader is, which can be quite destabilizing. This applies especially if the internal environment is characterized by strong politics and the leaders are jostling for power, which is often the case during restructurings, mergers and acquisitions, and outsourcing activities.

Involvement. Involvement in the change was indicated as an opportunity for employees to express themselves, to share their feelings and emotions and to access information more easily, resulting in more acceptance, pro-activity, motivation and commitment to the change. It was also identified as an instrument to change the mind of employees resisting the change. Giving responsibility to employees by involving them in the change, even if these employees are not motivated overall, fosters commitment to the change. And as one respondent explained, giving responsibility can also be used by management to express trust in the employee, which then motivates the employee to live up to management's expectations. The Belgian HR director of an international bank who had led a large restructuring program explained how she appointed two hundred change ambassadors. These were closely involved in the change and were continuously given information prior to general communications to the 4,500 employees of the organization. Although this group of two hundred employees was not a random sample, and generalization is therefore not possible, she indicated that employee turnover among these 200 people was considerably lower compared to the rest of the workforce. As an antonym for "involving," several respondents mentioned the word "imposition." An imposed change, thus with little opportunity for participation and involvement, will 
result in less synergy, less acceptance and a narrower focus on the benefits of the change, which all together results in more resistance to the change.

Personality. Personality was also said to be an important determinant of one's response to a change. People with an open, positive, flexible and risk-seeking personality were considered better able to deal with an organizational change or even to embrace change, while people who are more introvert, dogmatic and negative were characterized as not being supportive of change. A few respondents mentioned that people by nature seek security and will try to preserve the status quo, while any change, by definition, breaks the status quo.

Tenure. Tenure was mentioned as a factor that can influence the extent to which an individual employee is used to organizational change in general. Changing position, department or even organization is a considerable change in the life of an employee. Therefore, employees who have not changed position or organization often will probably have encountered fewer impactful changes to their daily work or working environment. As a result, these employees are likely to be less used to change and more opposed to change. Tenure was also indicated as a factor that shapes an employee's understanding of the context in which the organization is embedded. Employees who have worked in the same organization for many years and who have not seen many other organizations, their ways of working and their cultures, are likely to have less understanding of the context in which the current organization is embedded. As one respondent put it, these people develop barriers to think beyond their own immediate setting. The National Organization Development and Talent manager of a leading Spanish telecom company mentioned:

When you have changed, you have been working in different companies, you are younger [...] you can understand things that are happening out of [organization] [...] Perhaps you have more arguments to understand why you should change.

Change culture. Change culture represents the extent to which the collective of individuals in an organization is used to change. It was noted often that if employees are used to organizational change and it's in the DNA of the organization, it diminishes the anxiety and worries about a change and increases the employees' flexibility and their perception of change as a natural occurrence. The European HR director of a global company active in the welding industry explained that the majority of his employees had never worked in another industry, and many of those not even for another company. As a result, they were not particularly open to change, simply because they did not know that things can be done in different ways. He therefore initiated assignments to foster a change culture:

So as from this year, all of my guys, my teams, my HR local managers, they have an objective which is "go and benchmark a best-in-class type of company and share that with everybody in [organization]" [...] It just opens our mind. My goal is not maybe to come up with a lot of very good ideas, but my first objective is to have those guys going outside and see that there is a world outside of [organization] [...] And now they are in the mood of "yeah, we can do something $[\ldots]$ something different”.

Although frequent organizational changes help build a change culture in which employees are more open to change, it was also noted that people could then tire of change. However, respondents added that this would depend on the impact of prior organizational changes, as well as the nature of these changes, in particular whether they had positive or negative consequences for the individual employees.

Psychological contract on attitude

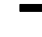


JOCM 29,2

Corporate culture. Corporate culture was put forward by various respondents as a set of values to which change initiatives are compared. As a Swiss OD manager explained, once employees no longer feel aligned with the corporate culture as a result of a change, they could decide to leave the organization. In line with this argumentation, an HR Vice-President who had worked in various European countries argued that during acquisitions or divestments, the shock regarding the other party's corporate culture largely determines how people react. It was furthermore stated repeatedly that the general nature of the approach to change chosen by management (e.g. a stepwise or a "big bang" approach), as well as the concrete change management practices, should fit in with this corporate culture in order to run a successful change program.

Labor unions. Various respondents mentioned the influence of labor unions on the change perceptions of employees, mainly in countries where employees are well protected by law, such as Belgium. In such countries any large organizational restructuring must be carefully discussed with the labor unions to prevent problems at a later stage. A Belgian HR director explained in detail the successful process of relocating a large store to another town. Individual solutions were offered to solve individual problems. However, the collectivistic perspective of the labor unions created a lot of problems as soon as a few disgruntled employees found their way to the labor unions. From that moment on, the individual solutions created for the majority of the employees did not hold. Similarly, an Italian national HR director of a global IT organization emphasized the importance of maintaining a good relationship with unions, because it helps a company to manage a transition. This would especially be the case in countries with protective labor legislation, where it is hard to implement large restructurings or to dismiss employees. As noted by a few interviewees, media can have a considerable influence on how employees perceive an organizational change, and labor unions can easily attract the attention of the media. A final argument put forward by an Italian transformation consultant was that strong protective labor legislation could slow down a transformation. The argumentation was that in this scenario, people would not feel a sense of personal urgency to adapt to the new situation, since they were protected by law, which results in passivity or resistance.

National differences. Several respondents mentioned the significance of national differences. Especially the notion of "national culture" was mentioned often, although the influence attributed to national culture varied among the respondents. Most noted that it is easier to implement changes in more collectivist Asian cultures like China, and that changes provoke less negative responses here than in more individualistic countries. In the latter countries it is more important for people to be involved and informed, and in the end it requires consensus to make a change work. It was also noted that corporate culture has the potential to overrule national culture, for example in a situation where an originally European organization has a subsidiary in Asia. It was stated that an individual's identification with the company and its culture is a stronger determinant of an employee's response to change than national culture. When considering the influence of national culture on employee responses to change, the European HR director of a global pharmaceutical organization colorfully explained how Americans were more open to organizational change than Europeans:

I mean Americans, an American family you know, an executive of 45-50 would think of nothing, would pack up his carpet, role the family in, and move to New York tomorrow, because he's got his new job there, whatever. In Europe, that's very hard. 
Psychological contract content. The content of the psychological contract was described as a pair of glasses through which the employee looks when evaluating the organizational change and attempting to answer the "what's in it for me" question. More specifically, the employee compares his or her understanding of what was promised and thus what he or she may expect to the anticipated individual impact, benefits or harms of the change. Thus, one's prior beliefs concerning the psychological contract contribute to shaping the answer to the "what's in it for me" question. What did I expect? How important it this to me? And what do I expect from the new situation after the change? One respondent noted that mapping these individual "what's in it for me" expectations would help management to live up to these expectations, and will thus lead to a more positive attitude to change. Another respondent applied the psychological contract to explain general differences in adaptability between certain economic sectors. He noted that the change mindset within in the psychological contracts of state employees will likely not be developed as much as, for example in high-tech businesses or consulting environments. He explained that in the latter economic sectors, which are highly influenced by the dynamics of their environment, adaptability is part of the culture and part of the psychological contract between an employee and the employer. Additionally, a Portuguese national HR director of a large bank explained that employees tend to be focussed on the negative parts of the psychological contract, while forgetting or taking for granted the basics and positive aspects. In their cultural change program they therefore deliberately emphasized the positive elements of the psychological contract of employees, with the aim of leveraging these elements to influence the answering of the "what's in it for me" question.

\section{Overruling categories}

Ability to change. Ability to change was identified as a factor that can overrule a positive answering of the "what's in it for me" question, thus putting the employee into negative mode. Several ability facets were mentioned by the respondents. First, an employee's ability to change was said to be influenced by the adequacy and quality of training, for example on how to use a newly implemented system. Another aspect mentioned was the availability of technology, such as a self-service application to contribute to a cultural change, making employees master of their own professional destiny. The European Talent manager of a global aluminum manufacturer provided a striking example of how the introduction of self-service via a computer at the plant resulted in an unexpected situation, in which employees simply did not have the ability to change:

We were laughing once, because a plant manager told me "how do you suppose [...] have you seen the hands of my workers?" he said. "Why?" "They are so big, that if they press one button on the keyboard, they click on three or four buttons". Ok, then you will only use some other things. But it's true. It's a practicality that you're missing sometimes when you work at this level.

Another factor mentioned often was the time available to change or to participate in the change process. As one respondent noted, the regular amount of workload can usurp all one's energy. Another respondent mentioned that in times of economic hardship, the workload and pressure is already very high, which makes it even more difficult for employees to change. A factor related to the amount of time available to change is the speed of the change. As noted several times, people simply need time to get used to the idea of change. A too high speed or a too narrow timeframe for implementing the 
JOCM 29,2

282 change hinders employees in getting acquainted with the new way of working and/or the change of mindset.

Availability of alternatives. The availability of alternatives is another factor that can overrule one's evaluation of the change. Respondents indicated that if market conditions make it hard for employees to find a new suitable job elsewhere, they are likely to respond more positively to the change, even if the expected outcome is not as beneficial for the employee as he or she might like. In such a situation the actual attitude toward change is thus driven by job security considerations. In a situation where there are plenty of external opportunities, there is less need for constructive change behavior if the change is expected to be detrimental to the individual employee. Additionally, it was noted that the private situation can prevent an employee from taking any risks that could harm his or her financial position, which consequently influences his or her attitude toward a change. As a Dutch People Strategy manager noted, there is a big difference in how you respond to change when you have been with the company for 30 years, you have a mortgage and you are the household income earner, than when you are a 20-year-old talent in a completely different phase of life, with less financial obligations.

Trust. Trust is another overruling factor mentioned frequently as a central factor determining one's attitude to a change. According to the respondents, trust in management and leadership results in a more positive attitude toward change and more willingness to embrace the change. Conversely, if the employment relationship is characterized by mistrust resulting from multiple negative experiences of seeing trust broken, it is hard to mobilize employees a next time. Trust can therefore be an important enabler of organizational change. A French implementation professional illustrated the overruling capacity of trust, stating that trust in management or the company in general could turn an uncomfortable situation into a comfortable one. The interviews also made clear that an individual employee can have trust in the organization as a whole, in management as a group of people, or in a specific manager or leader. In this respect, it was mentioned by several respondents that a leader is not necessarily the direct supervisor but can also be an informal leader or former hierarchical leader. Depending on the context of the change, either a group or an individual can represent leadership that is trusted. For example, a Dutch manager noted that an employee wants to trust the organization to take the right decisions regarding the change in general. Yet when it comes to the "what's in it for me" question, trust in the direct supervisor was said to be the most crucial determinant of one's attitude to change. In line with this observation, a French HR director explained that simply saying "trust me" to employees can be very powerful during a change process, especially when you as management cannot disclose all the information you have. Since the leader can be represented by various roles or people in different situations, the Belgian director of a global IT organization emphasized the importance of a set of shared values. Indeed, as an Italian deputy HR director stressed, when employees perceive a gap between personal or professional values and company values, this results in mistrust. Most of the comments on trust made by the respondents related to the trust underlying the employment relationship. However, trust in the change throughout the entire change process was addressed as well. Management should act in accordance with promises earlier on in the change process, that is, it must walk the talk. If not, employees will become suspicious which can then result in mistrust.

Psychological contract state. The state of the psychological contract, or in other words the extent to which implicit and explicit promises have been fulfilled by an 
organization, was mentioned by the respondents as being an important determinant of one's eventual attitude to a change. If an organization is perceived by an employee to repeatedly live up to its promises, trust is created which results in more commitment, support, positive contributions and willingness to change. On the other hand, a history of unfulfilled promises results in mistrust, which was indicated by the interviewees to cause skepticism, suspicion, caution, temporization and passiveness regarding the change. Actual employee turnover was also mentioned as an outcome, since a lack of trust resulting from repeatedly unfulfilled promises undermines an employee's faith that the change may herald a shift in this tradition of under-fulfillment of promises. Furthermore, it was noted that a well-fulfilled psychological contract serves as a buffer that prevents employees from immediately going into a negative mode as soon as a negative event occurs during the course of a change program.

In a few divergent comments, respondents indicated that a well-fulfilled psychological contract could result in negative responses to a change, since it means that the outcome of the change could potentially be less optimal for the employee, and that the organization might no longer be able to fulfill its promises as it did in the past. On the other hand, a few respondents stated that an unfulfilled psychological contract could lead to a positive attitude to a change, since it might mean that the organization will be better able to live up to its promises in the future. However, the common line of reasoning was that well-fulfilled psychological contracts create trust, which consequently leads to a positive attitude to organizational change.

When considering the fulfillment of the employee-side of the psychological contract, the main line of reasoning was that employees who felt they did a good job in fulfilling their promises were more engaged, resulting in a more positive attitude to a change. They would be more open to change, cooperate more in the change process and maintain a high level of productivity. According the most respondents, they would also see the change as an opportunity, and believe they have nothing to fear from the change. In case of an unfulfilled employee side of the psychological contract, the employee is already disengaged, which most likely results in negative responses to change such as passiveness, reluctance, criticism, attempts to protect the status quo and anxiety that their under-performance will no longer be accepted. However, several respondents also raised the rhetorical question of how many employees will feel that they fail to fulfill their side of the psychological contract.

Although a well-fulfilled employee-side of the psychological contract suggests a good level of engagement that is likely to lead to a positive response to a change, the interviewees emphasized that it could also jeopardize one's cooperation with the change. Employees who feel they have fulfilled or even over-fulfilled their promises to the organization might perceive a sense of entitlement, which could lead to a sense of betrayal, insufficient recognition or insufficient involvement in the change or the decision-making process. This could subsequently lead to negative responses to the organizational change.

\section{The conceptual model}

As explained in detail in the method section, the conceptual model of this study was constructed during the iterative selective coding process. This model comprises all 21 categories described in the first part of this results section, and is presented in Figure 1.

First, the conceptual model shows that the attitude toward change cluster comprises the outcome categories "Affective," "Behavioral" and "Cognitive," which indicates that 


\section{JOCM \\ 29,2}

284

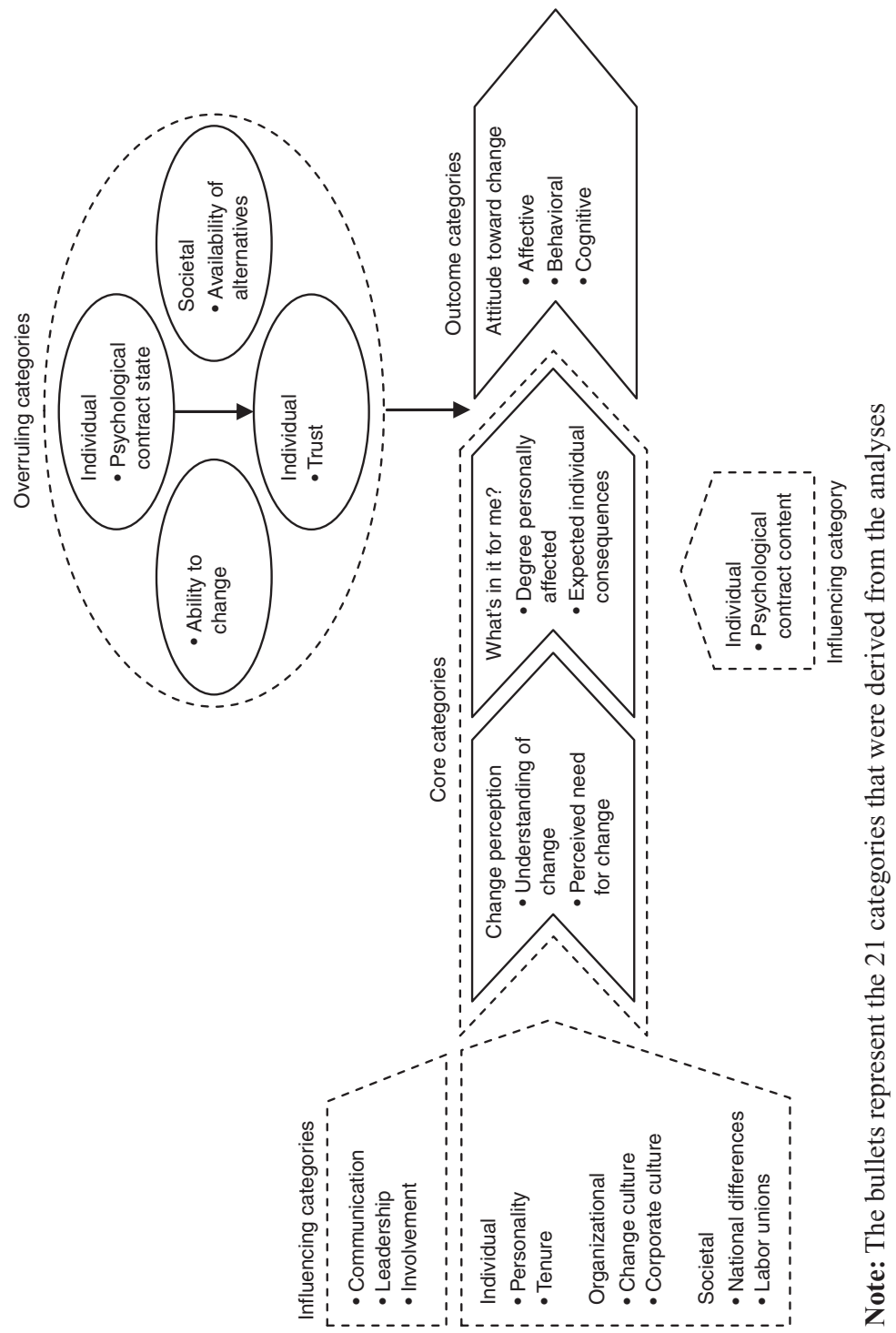

Figure 1.

Attitude toward change model 
a focus on only one or two of these response components produces an incomplete picture of an employee's attitude toward a change.

Second, at the center of the model, the four core categories are positioned as main determinants of an employee's attitude toward change. The cluster change perception, which comprises the core categories "Understanding of change" and "Perceived need for change," concerns their general perception of the vision behind the change, its rationale and the change process ahead. The change perceptions subsequently determine the employees' individual answer to the what's in it for me question. This cluster, which comprises the core categories "Degree personally affected" and "Expected individual consequences," concerns the individual evaluation of whether the change is beneficial for this particular individual employee, rather than for the organization as a whole or for a team. If the assessment of the "what's in it for me" question produces as positive answer, an individual's attitude toward change will be positive as well, while a negative outcome results in negative affective, behavioral and cognitive responses to a change.

Third, the model depicts the influencing categories presented in the first part of this results section. When applying Oreg et al.'s (2011) distinction between change and pre-change antecedents, three influencing categories can be labeled as change antecedents, namely, "Communication," "Leadership" and "Involvement." Pre-change influencing categories at an individual level are "Personality," "Tenure" and "Psychological contract content." At an organizational level the pre-change influencing categories are "Change culture" and "Corporate culture." Further, the pre-change influencing categories at a societal level are "National differences" and "Labor unions." Except for "Psychological contract content," all influencing variables were found to be influencers of the core cluster of change perception. These influencing categories frame the perception of an individual employee about an organizational change. The influence category of "Psychological contract content," on the other hand, influences the core cluster of "what's in it for me." Thus, the content of the psychological contract influences the individual evaluation of whether the organizational change will be beneficial or harmful for the particular individual employee.

Fourth, the model includes the four overruling categories "Ability to change" (change antecedent), "Availability of alternatives" (pre-change antecedent, societal level), "Trust" and "Psychological contract state" (pre-change antecedents, individual level). Although a positive evaluation of the "what's in it for me question" generally results in a positive attitude toward change and vice versa, these overruling categories have the potential to reverse this relationship. Thus, even if change is perceived by the individual employee as beneficial for oneself, a lack of ability to change, a lack of trust in management, or the availability of alternative jobs elsewhere might still cause negative responses. The overruling category of "Psychological contract state" is positioned as an important determinant of the overruling variable "Trust." Thus, a lack of psychological contract fulfillment causes a decrease in trust in the organization and its representatives. All overruling variables have the potential to transform a negative evaluation of the "what's in it for me question" into a positive attitude toward change as well. For example, a history of fulfilled promises creates high levels of trust and might give management the benefit of the doubt if negative individual consequences are expected in times of organizational change.

In the following discussion section, the three research questions as presented in the introduction will be answered. Furthermore, the implications of the results for researchers and practitioners are presented.
Psychological contract on attitude 
JOCM

29,2

\section{Discussion}

The principal purpose of this research was to acquire more insight into the managerial perspective on how the psychological contract influences an employee's attitude toward change. The results demonstrate that, according to managers, the content of the psychological contract influences the employee's own ideas on the "what's in it for me question," i.e. on the extent to which the organizational change will prove personally beneficial. The state of the psychological contract was furthermore identified as an overruling factor with the potential of reversing a positive evaluation of the "what's in it for me" question into a negative attitude toward change and vice versa.

Concerning the extent to which the three-dimensional construct of attitude toward change can be justified and which factors influence these attitudes toward organizational change, the results demonstrate that managers witness a wide variety of affective, behavioral and cognitive responses. Respondents also indicated that these feelings, behaviors and thoughts can coexist and range from very negative to very positive. The results of this study therefore demonstrate that the adoption of the neutrally phrased and multidimensional attitude toward change construct can be justified.

The results furthermore reveal 18 antecedent categories that, according to managers, determine the attitude of employees to organizational change. The analyses reveal: first, core categories, which concern the employees' change perception and the individual "what's in it for me" question; second, influencing categories that influence these core categories; and third, categories that have the potential to overrule the theoretically and logically presumed relationship between that answer to the "what's in it for me" question and the consequent attitude toward change. The overruling categories are therefore decisive determinants of the eventual affective, behavioral and cognitive responses of employees to organizational change.

The results of this study have implications for researchers as well as for practitioners. In the remainder of this discussion section, these implications with related limitations and research recommendations are discussed.

The first implication concerns the contribution of this study to understanding sensemaking processes in times of organizational change. As Bartunek et al. (2006) have emphasized, a change recipient's perception of organizational change "may be both consistent with and diverge from what change agents intend" (p. 202). The individual's perception of the change was found to be one of the core determinants of attitude toward change. However, this primarily cognitive sense-making process is influenced by various variables, of which many cannot or not easily be influenced by organizational leaders and change managers. This relates to the distinction between pre-change and change antecedents, in which pre-change antecedents are not directly linked to a particular organizational change. As noted by Oreg et al. (2011), most quantitative studies on attitude toward change research have focussed on the influence of change process antecedents, such as participation, communication and procedural fairness. However, as demonstrated here, most antecedent categories are not related to a particular organizational change, but rather to the general state of the employment relationship. Factors such as trust and change culture, for example, primarily concern the situation prior to the introduction of the organizational change. Since these factors shape the individual's perception and evaluation of the change, they should be carefully considered by management during the planning and designing stages of a specific change. Furthermore, the present study demonstrates the central role of the psychological contract in the sense-making process. Fulfillment of the psychological contract creates trust, which can compensate worries about the individual negative 
consequences of the change. Additionally, the evaluation of the change depends not only on the individual perception of the change, but also on the content of the psychological contract. Empirical quantitative research on the relationship between the psychological contract and employee responses to change is scarce, however. Research on the antecedents of attitude toward change can therefore benefit from the inclusion of general quality indicators of the state of the employment relationship such as trust, commitment, engagement and the psychological contract. This is of particular interest as these factors influence the sense-making process, and thus the general perception of an organizational change. Moreover, as demonstrated here, these factors can explain why employees sometimes respond contrary to what is expected by change agents, who often place much emphasis on the change process itself and disregard the general employment context. However, as Herold et al. (2007) concluded, "organizations cannot roll out change after change assuming that each change is an independent event" without carefully considering "extrachange factors, such as the workplace setting in which the change is occurring" (p. 949). To conclude, change agents can benefit from an increased focus on pre-change antecedents, which are perhaps hard to influence in the short term but that do largely shape the employee's perception of an organizational change. If an increased focus on pre-change antecedents is combined with change management and communication practices that: first, focus on the individual's understanding of a change; second, intend to dispel questions about the change in the heads of employees; and third, consequently segment information with a view to individual needs, the likelihood of positive change attitudes will increase.

The second implication of this research concerns the adoption of the managerial perspective. Management plays a crucial role in both pre-change and change antecedent categories such as communication, change culture, corporate culture, psychological contract content, psychological contract state and trust. It is crucial that managers have insight into employees' needs, expectations and perception of promises. Business leaders and change managers with a lack of sincere interest in the psychological contracts of their employees are likely to be confronted with unexpected and unpredictable attitudes toward organizational change. In times of change employees are triggered to evaluate their psychological contracts (Guzzo et al., 1994), and to examine whether the deal made earlier in the employment relationship is still intact. This implies an evaluation of whether the exchange relationship is still well balanced. Moreover, during changes managers are more likely to be unable or unwilling to live up to promises made previously (Morrison and Robinson, 1997). Knowledge of and a strong emphasis on the psychological contract before as well as during organizational changes therefore seems a necessity rather than a desirability.

This study only addressed the managerial perspective on the antecedents of attitude toward change, while a vast amount of prior empirical research has focussed on the employee's perspective. The question that has to be addressed is whether or not the managerial beliefs are supported by empirical evidence on employee views. If it turns out that employee views are different, managerial practices and interventions might very well be ineffective or even counterproductive. A recommendation for future research would therefore be to study both perspectives in a single organizational change context, and to identify whether there is a discrepancy between the two perspectives. More insight into the causes and consequences of discrepancies in views on individual needs, expectations and perceived promises would enable the identification of the relative importance of pre-change and change antecedents, as well as the importance of the psychological contract as pre-change antecedent. 
JOCM 29,2

288

The third implication concerns the multidimensional conceptualization of the attitude toward change construct. Although early writings about employee responses to change mainly focussed on behavioral reactions, the affective and cognitive responses have been considered in recent decades as well. The recent adoption of the tripartite attitude toward change in conceptual as well as empirical research acknowledges the coexistence of divergent feelings, behaviors and thoughts in times of change and admits that these dimensions can be ambivalent (Piderit, 2000). The present research contributes to the understanding of the attitude toward change construct by demonstrating the broad variety of potential affective, behavioral and cognitive responses to change and by showing that these responses should be considered as a continuum ranging from highly negative to very positive. Future research can benefit from using the more neutrally phrased and all-embracing attitude toward change construct rather than one-dimensional negative or positive concepts.

Future research could furthermore examine the sequential relationship between the three attitude dimensions. According to affective event theory, affective responses predict behavioral and cognitive responses, while the tripartite view on attitudes assumes that the three dimensions cause variations in the global attitude (Piderit, 2000). The ongoing debate on these two divergent perspectives could benefit from longitudinal empirical research on the multidimensional attitude toward change perspective. Our results demonstrate that in addition to observable behaviors, change agents should also consider the feelings and thoughts of employees when attempting to predict the failure or success of an organizational change. Although the important role of feelings and thoughts in a change process is indeed acknowledged in most change management approaches, change managers are often at a loss how to consider or effectively manage these affective and cognitive responses. Although less visible, the effect of affective and cognitive responses is however likely to have a long-lasting influence, and may emerge as emotional exhaustion, burnout or quitting. Another reason for the inappropriate management of feelings and thoughts during change processes could be that the consideration of affective and cognitive responses requires mutual trust and an open dialogue between the individual employee and the individual manager. Such a dialogue can be difficult to achieve for both parties, especially if the manager is or is held to be responsible for negative consequences of the change or a potential breach of the employee's psychological contract.

An important limitation of this study is that we could not consider whether the influence of antecedents differs between attitude dimensions. The question whether certain antecedents are better predictors for affective response to change and others for the behavioral or cognitive responses was not addressed. In a study by Van den Heuvel and Schalk (2009), for example, psychological contract fulfillment was only related to the affective dimension of attitude toward change, disregarding the behavioral and cognitive dimensions. This issue could also be addressed in future research. Similarly, the work-related outcomes of attitude toward change can be expected to differ for the attitude dimension as well. Oreg (2006), for example, assessed the influence of all three attitude toward change dimensions on job satisfaction, intention to quit and continuance commitment. The results showed that only the affective dimension influenced job satisfaction, only the behavioral dimension influenced intention to quit, and only the cognitive dimension influenced continuance commitment.

Another limitation of this study concerns the context in which it was performed. Given its explorative nature, the chosen approach aimed to include respondents active in various organizations, economic sectors and countries. As a result, various types of 
organizational change and groups of employees were considered, resulting in a broad perspective on attitudes toward change that is applicable to various organizational contexts. However, this approach has limitations as well. The fairly small sample size per country, for example, did not allow for a profound and country-specific argumentation regarding the influence of legislation, national culture and labor unions. Additionally, as all interviews were conducted in Europe, cultural differences between the countries are likely to be relatively small, compared to cultural differences between, for example Europe and Asia or South America. Future research would therefore benefit from the inclusion of respondents from these various cultural settings to enable a comparison between cultures and to increase the validity of generalizations toward countries and cultures. This is especially relevant when studying the influence of the psychological contract on attitude toward change, since national cultures "have a bearing on the way psychological contracts function in the interplay between employers and employees" (Schalk and Soeters, 2008, p. 118). Another limitation of the data collection approach concerns the large diversity in economic sectors in which interviews were conducted. No explicit distinction was made regarding the level of the employees active in these sectors, for example between blue collar work and white collar work. An exclusive focus on a specific group, such as highly educated researchers or blue collar engineers, may yield valuable insights into motivations, perceptions and sense-making processes among these specific employees in times of change. Furthermore, no governmental organizations were included in the sample, which leaves this sector - stereotypically assumed to be a less dynamic work environment with generally higher levels of resistance to change - unexamined. A recommendation for future research on the antecedents of attitude toward change, in particular the psychological contract, is to consider specific types of organizational change, industrial sectors and employee groups, and to increase cross-country and cross-cultural comparisons. By doing so, we can gradually increase our understanding of how the psychological contract influences employees' affective, behavioral and cognitive responses to organizational change.

\section{References}

Agócs, C. (1997), "Institutionalized resistance to organizational change: denial, inaction, and repression", Journal of Business Ethics, Vol. 16 No. 9, pp. 917-931. doi: 10.1023/A:1017939404578.

Argyris, C. (1960), Understanding Organizational Behavior, Tavistock Publications, London.

Bagozzi, R.P. (1978), "The construct validity of the affective, behavioral, and cognitive components of attitude by analysis of covariance structures", Multivariate Behavioral Research, Vol. 13 No. 1, pp. 9-31. doi: 10.1207/s15327906mbr1301_2.

Baker, T.L. (1999), Doing Social Research, 3rd ed., McGraw-Hill, New York, NY.

Bartunek, J.M., Rousseau, D.M., Rudolph, J.W. and DePalma, J. (2006), "On the receiving end: sensemaking, emotion, and assessments of an organizational change initiated by others", Lournal of Applied Behavior Science, Vol. 42 No. 2, pp. 182-206. doi: 10.1177/ 0021886305285455 .

Bouckenooghe, D. (2010), "Positioning change recipients' attitudes toward change in the organizational change literature", Iournal of Applied Behavioral Science, Vol. 46 No. 4, pp. 500-531. doi: 10.1177/0021886310367944.

Chen, J. and Wang, L. (2007), "Locus of control and the three components of commitment to change", Personality and Individual Differences, Vol. 42 No. 3, pp. 503-512. doi: 10.1016/j. paid.2006.07.025. 
JOCM 29,2
Dabos, G.E. and Rousseau, D.M. (2004), "Mutuality and reciprocity in the psychological contracts of employees and employers", Lournal of Applied Psychology, Vol. 89 No. 1, pp. 52-72. doi: 10.1037/0021-9010.89.1.52.

Dougherty, D. (2004), "Organizing practices in services: capturing practice-based knowledge for innovation”, Strategic Organization, Vol. 2 No. 1, pp. 35-64. doi: 10.1177/1476127004040914.

Eagly, A.H. and Chaiken, S. (1998), "Attitude structure and function", in Gilbert, D.T., Fiske, S.T. and Lindsey, G. (Eds), Handbook of Social Psychology, McGraw-Hill, Boston, MA, pp. 269-322.

Elias, S.M. (2009), "Employee commitment in times of change: assessing the importance of attitudes toward organizational change", Lournal of Management, Vol. 35 No. 1, pp. 37-55. doi: 10.1177/0149206307308910.

Elizur, D. and Guttman, L. (1976), "The structure of attitudes toward work and technological change within an organization", Administrative Science Quarterlv, Vol. 21 No. 4, pp. 611-622.

Folger, R. and Skarlicki, D.P. (1999), "Unfairness and resistance to change: hardship as mistreatment", Lournal of Organizational Change Management, Vol. 12 No. 1, pp. 35-50. doi: $10.2307 / 256877$.

Freese, C. (2007), "Organizational change and the dynamics of psychological contracts: a longitudinal study", doctoral dissertation, Tilburg University, Tilburg.

Guest, D. (2004), "The psychology of the employment relationship: an analysis based on the psychological contract”, Applied Psychology, Vol. 53 No. 4, pp. 541-555. doi: 10.1111/j.14640597.2004.00187.x.

Guzzo, R.A., Noonan, K.A. and Elron, E. (1994), "Expatriate managers and the psychological contract”, Journal of Applied Psychology, Vol. 79 No. 4, pp. 617-626. doi: 10.1037//00219010.79.4.617.

Herold, D.M., Fedor, D.B. and Caldwell, S.D. (2007), "Beyond change management: a multilevel investigation of contextual and personal influences on employees' commitment to change", Iournal of Atplied Psychology, Vol. 92 No. 4, pp. 942-951. doi: 10.1037/0021-9010.92.4.942.

Holt, D.T., Armenakis, A.A., Feild, H.S. and Harris, S.G. (2007), "Readiness for organizational change: the systematic development of a scale", Iournal of Athlied Behavioral Science, Vol. 43 No. 2, pp. 232-255. doi: 10.1177/0021886310396550.

Johnson, J.L. and O'Leary-Kelly, A.M. (2003), "The effects of psychological contract breach and organizational cynicism: not all social exchange violations are created equal", Lournal of Organizational Behavior, Vol. 24 No. 5, pp. 627-647. doi: 10.1002/job.207.

Kavanagh, M.H. and Ashkanasy, N.M. (2006), "The impact of leadership and change management strategy on organizational culture and individual acceptance of change during a merger", British Journal of Management, Vol. 17 No. S1, pp. S81-S103. doi: 10.1111/j.1467-8551.2006.00480.x.

Kickul, J., Lester, S.W. and Belgio, E. (2004), "Attitudinal and behavioral outcomes of psychological contract breach. A cross-cultural comparison of the United States and Hong Kong Chinese", International Journal of Cross Cultural Management, Vol. 4 No. 2, pp. 229-252. doi: 10.1177/1470595804044751.

Lester, S.W., Kickul, J.R. and Bergmann, T.J. (2007), "Managing employee perceptions of the psychological contract over time: the role of employer social accounts and contract fulfillment", Journal of Organizational Behavior, Vol. 28 No. 2, pp. 191-208. doi: 10.1002/job.410.

Levinson, H., Price, C.R., Munden, K.J., Mandl, H.J. and Solley, C.M. (1962), Men, Management and Mental Health, Harvard University Press, Cambridge, MA.

Lincoln, Y.S. and Guba, E.G. (1985), Naturalistic Inquiry, Sage Publications, Newbury Park, CA.

Lines, R. (2005), "The structure and function of attitudes toward change", Human Resource Development, Vol. 4 No. 1, pp. 8-32. doi: 10.1177/1534484304273818. 
McCarthy, D.J., Puffer, S.M., May, R.C., Ledgerwood, D.E. and Stewart, W.H. Jr (2008), "Overcoming resistance to change in Russian organizations: the legacy of transactional leadership”, Organizational Dvnamics, Vol. 37 No. 3, pp. 221-235. doi: 10.1016/j. orgdyn.2008.04.002.

Morrison, E.W. and Robinson, S.L. (1997), "When employees feel betrayed: a model of how psychological contract violation develops", Academy of Management Review, Vol. 22 No. 1, pp. 226-256. doi: 10.2307/259230.

Oreg, S. (2003), "Resistance to change: developing an individual differences measure", Lournal of Applied Psychology, Vol. 88 No. 4, pp. 680-693. doi: 10.1037/0021-9010.88.4.680.

Oreg, S. (2006), "Personality, context, and resistance to organizational change", European Iournal of Work and Organizational Psychology, Vol. 15 No. 1, pp. 73-101. doi: 10.1080/ 13594320500451247.

Oreg, S., Vakola, M. and Armenakis, A. (2011), "Change recipients' reactions to organizational change: a 60-year review of quantitative studies", Iournal of Applied Behavioral Science, Vol. 47 No. 4, pp. 461-524. doi: 10.1177/0021886310396550.

Ostrom, T.M. (1969), "The relationship between the affective, behavioral, and cognitive components of attitude", Lournal of Experimental Social Psvchologv, Vol. 5 No. 1, pp. 12-30.

Pate, J., Martin, G. and Staines, H. (2000), "Exploring the relationship between psychological contracts and organizational change: a process model and case study evidence", Strategic Change, Vol. 9 No. 8, pp. 481-493. doi: 10.1002/1099-1697(200012)9:8<481::AIDJSC513>3.0.CO;2-G.

Piderit, S.K. (2000), "Rethinking resistance and recognizing ambivalence: a multidimensional view of attitudes toward an organizational change", Academy of Management Review, Vol. 25 No. 4, pp. 783-794. doi: 10.2307/259206.

Robinson, S.L. (1996), "Trust and breach of the psychological contract", Administrative Science Quarterlv, Vol. 41 No. 4, pp. 574-599. doi: 10.2307/2393868.

Robinson, S.L. and Rousseau, D.M. (1994), "Violating the psychological contract: not the exception but the norm", Iournal of Organizational Behavior, Vol. 15 No. 3, pp. 245-259. doi: 10.1002/job.4030150306.

Rousseau, D.M. (1990), "New hire perceptions of their own and their employer's obligations: a study of psychological contracts", Lournal of Organizational Behavior, Vol. 11 No. 5, pp. 389-400. doi: 10.1002/job.4030110506.

Rousseau, D.M. (1996), "Changing the deal while keeping the people”, Academy of Management Executive, Vol. 10 No. 1, pp. 50-61. doi: 10.5465/AME.1996.9603293198.

Rousseau, D.M. (1998), “The 'problem' of the psychological contract considered”, Iournal of Organizational Behavior, Vol. 19 No. S1, pp. 665-671. doi: 10.1002/(SICI)1099-1379(1998) 19:1+<665::AID-JOB972>3.0.CO;2-X.

Rousseau, D.M. (2003), "Extending the psychology of the psychological contract: a reply to putting psychology back into psychological contracts", Journal of Management Inquiry, Vol. 12 No. 3, pp. 229-238. doi: 10.1177/1056492603256339.

Rousseau, D.M. and Tijoriwala, S.A. (1999), "What's a good reason to change? Motivated reasoning and social accounts in promoting organizational change", Journal of Applied Psvchologv, Vol. 84 No. 4, pp. 514-528. doi: 10.1037//0021-9010.84.4.514.

Schalk, R. and Soeters, J.M.M.L. (2008), "Psychological contracts across the world. Cultural agreements and disagreements", in Smith, P.B., Peterson, M.F. and Tomas, D.C. (Eds), Handbook of Cross-Cultural Management Research, Sage, Thousand Oaks, CA, pp. 117-133.

Schein, E.H. (1965), Organizational Psychology, Prentice-Hall, Englewood Cliffs, NJ. 
JOCM 29,2
Spencer, L., Ritchie, J. and O'Connor, W. (2003a), “Analysis: practices, principles and processes”, in Ritchie, J. and Lewis, J. (Eds), Qualitative Research Practice: A Guide for Social Science Students and Researchers, Sage Publications, London, pp. 219-262.

Spencer, L., Ritchie, J. and O'Connor, W. (2003b), "Carrying out qualitative analysis", in Ritchie, J. and Lewis, J. (Eds), Qualitative Research Practice: A Guide for Social Science Students and Researchers, Sage Publications, London, pp. 219-262.

Stanley, D.J., Meyer, J.P. and Topolnytsky, L. (2005), "Employee cynicism and resistance to organizational change", Journal of Business and Psychology, Vol. 19 No. 4, pp. 429-459. doi: 10.1007/s10869-005-4518-2.

Strauss, A. and Corbin, J. (1990), Basics of Grounded Theory Methods, Sage, Beverly Hills, CA.

Strauss, A. and Corbin, J. (1998), Basics of Qualitative Research: Grounded theory Procedures and Techniques, 2nd ed., Sage, Thousand Oaks, CA.

Tekleab, A.G., Takeuchi, R. and Taylor, M.S. (2005), "Extending the chain of relationships among organizational justice, social exchange, and employee reactions: the role of contract violations", Academy of Management Iournal, Vol. 48 No. 1, pp. 146-157. doi: 10.5465/AMJ.2005.15993162.

Turnley, W.H. and Feldman, D.C. (2000), "Re-examining the effect of psychological contract violations: unmet expectations and job dissatisfaction as mediators", Iournal of Organizational Behavior, Vol. 21 No. 1, pp. 25-42. doi: 10.1002/(SICI)1099-1379(200002) 21:1<25::AID-JOB2>3.0.CO;2-Z.

Turnley, W.H., Bolino, M.C., Lester, S.W. and Bloodgood, J.M. (2003), "The impact of psychological contract fulfillment on the performance of in-role and organizational citizenship behaviors", Journal of Management, Vol. 29 No. 2, pp. 187-206. doi: 10.1177/ 014920630302900204.

Van den Heuvel, S. and Schalk, R. (2009), "The relationship between fulfilment of the psychological contract and resistance to change during organizational transformations", Social Science Information, Vol. 48 No. 2, pp. 283-313. doi: 10.1177/0539018409102415.

Wanberg, C.R. and Banas, J.T. (2000), "Predictors and outcomes of openness to changes in a reorganizing workplace", Iournal of Athlied Psvchologv, Vol. 85 No. 1, pp. 132-142. doi: 10.1037/0021-9010.85.1.132.

Zhao, H., Wayne, S.J., Glibkowski, B.C. and Bravo, J. (2007), “The impact of psychological contract breach on work-related outcomes: a meta-analysis", Personnel Psvchologv, Vol. 60 No. 3, pp. 647-680. doi: 10.1111/j.1744-6570.2007.00087.x.

\section{Corresponding author}

Sjoerd van den Heuvel can be contacted at: s.r.h.vandenheuvel@utwente.nl

For instructions on how to order reprints of this article, please visit our website: 